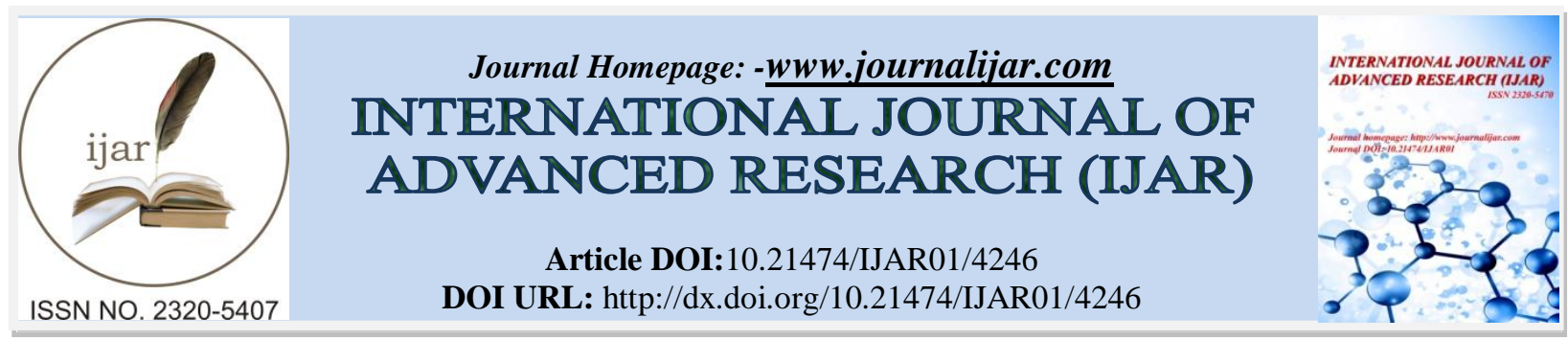

RESEARCH ARTICLE

\title{
EFFICACY OF VARIOUS SCAR REVISION TECHNIQUES IN MAXILLOFACIAL REGION- A PROSPECTIVE DOUBLE-BLIND STUDY.
}

\author{
Dr Tanya Sethi (BDS) ${ }^{1}$, Dr Vijayendra Kumar (MDS) ${ }^{2}$, Dr Shreya Gour (MDS) ${ }^{3}$ and Dr Devika Gupta \\ $(\text { BDS })^{1}$.
}

1. Kanpur, U.P, India.

2. Reader,Department of Oral \& Maxillofacial Surgery,Rama Dental College- Hospital \& Research Centre, Kanpur,U.P, India.

3. Consultant Pathologist,Hyderabad, Telangana, India.

\section{Manuscript Info}

Manuscript History

Received: 24 March 2017

Final Accepted: 26 April 2017

Published: May 2017

Key words:-

Scars, Hypertrophic scars, wound closure techniques, Esthetic surgery, Revision, Cicatrix, Cheek, Nasolabial fold.

\section{Abstract}

Aim- Facial scars cause both psychological and aesthetical torment to the patient's and have a distressing impact on their quality of life and self esteem. Scar revision surgeries require diligent caring and solely depends on surgeon's perception of pleasant aesthetic features. As there is no 'cook book' approach to scar revision, it requires some talent and honing of skills. Here we present a research study on management of facial scars, through various revision techniques and compare their efficacy in restoring normal anatomy, with minimal complications.

Methods- This study was undertaken in our tertiary care center, over a period of two years. 96 patients were selected with disfiguring scars caused mainly due to trauma, burns or other iatrogenic factors. Techniques of scar revision included $\mathrm{Z}$ plasty, $\mathrm{W}$ plasty and VY plasty.

Results-The scar revision surgery yielded excellent results. Complications were encountered in 5\% of cases, namely, haematoma formation, secondary infection and delayed healing. Regarding the efficacy of scar revision, excellent improvement was seen in $60 \%$ patients, moderate improvement was seen in $30 \%$ patients and mild improvement was seen in $10 \%$ patients.

Conclusions: Various surgical scar revision techniques can be done to treat specific types of scars, based on their size and site. A thorough knowledge of skin physiology, biomechanics, facial aesthetic principles, and the surgical geometry of soft-tissue surgery is mandatory for the surgeon and can help in minimizing the scarring.

Copy Right, IJAR, 2017,. All rights reserved.

\section{Introduction:-}

A scar is the fibrous tissue that remains after a wound is healed. ${ }^{1}$ The severity of scar formation is generally related to the amount of skin damage, healing time, patient's age, and the location on the body. Although most scars fade as they mature over time, some remain noticeable. Whether such a scar is acceptable or unacceptable depends on the degree of functional or cosmetic impairment and the patient's perceptions. ${ }^{2}$ Facial scar revision presents a challenge 
to the maxillofacial surgeon and considered to be among the most important skills in the surgeon's armamentarium. ${ }^{(3-5)}$ When evaluating a patient with a functionally or cosmetically undesirable facial scar, the surgeon must be prepared to deal with the technical, physical, and psychological issues in order to determine if the patient is a candidate for revision and to explore the impact of the scar on the patient's life, examine the characteristics of the scar, and discuss the patient's expectations with realistic treatment options. ${ }^{(6-8)}$

Scar analysis should be done to determine technical feasibility and options for revision. The quality of a scar is evaluated by rating its color, width, depth, location, and orientation. ' Ideally the color of a scar should closely match that of the surrounding tissue. For optimal aesthetic outcome, the scar should be narrow, flat, and positioned between skin folds or wrinkles. ${ }^{10}$ Timing of scar revision is based on age of scar and nature of the wound. Every attempt should be made to convert a suboptimal scar into an ideal scar although it may not be always possible.

\section{Material and Methods:-}

The aim of our study, was to evaluate the efficacy of various scar revision techniques including Z plasty, VY plasty and W plasty. The study was done in our hospital from September 2014 to December 2016 and a total of 96 patients were included in the study, having facial scars caused by either trauma, burns or iatrogenic factors. Written informed consent was taken from all the patients before the surgery and ethical committee approval was taken. Pre and post operative photographs were taken of all the patients. Proper counseling of all the patients was done and the patients expectations were brought to realistic level. Patients having history of keloid formation, bleeding disorders, on oral anticoagulants and uncontrolled diabetes were excluded from the study. For assessing the efficacy of treatment, the patients were divided into three groups: Excellent results - More than 90\% improvement after scar revision, Moderate results - 75\% - 90\% improvement after scar revision and Poor results - 25\% - 50\% improvement after scar revision. The data was collected, tabulated and the results were analyzed statistically using chi square test.

\section{Results:-}

Out of 96 patients, 78 were males and 18 were females, male:female ratio was 4.3:1. Age distribution ranged from 19 to 55 years (Table 1). Maximum number of patients operated for facial scars, were in the range of 21-40 years of age $(50 \%)$.

Table 1:-Age distribution of patients.

\begin{tabular}{|c|c|c|c|}
\hline S.no. & Age Distribution & Number & Percentage \\
\hline 1 & $0-20$ & 22 & $23 \%$ \\
\hline 2 & $21-40$ & 48 & $50 \%$ \\
\hline 3 & $41-60$ & 26 & $27 \%$ \\
\hline
\end{tabular}

Surgical revision techniques used were $\mathrm{Z}$ plasty in 52 patients (54\%), W plasty in 35 patients (36\%) and VY plasty in 9 patients $(10 \%)$. (Table 2)

Table 2:- Surgical revision techniques.

\begin{tabular}{|c|c|c|c|}
\hline S.no. & Surgical procedures & Number & Percentage \\
\hline 1 & Z plasty & 52 & $54 \%$ \\
\hline 2 & W plasty & 35 & $36 \%$ \\
\hline 3 & VY plasty & 9 & $10 \%$ \\
\hline
\end{tabular}

Regarding the efficacy of scar revision, excellent improvement was seen in $57(60 \%)$ patients, moderate improvement was seen in $29(30 \%)$ patients and mild improvement was seen in $10(10 \%)$ patients. (Table 3)

Table 3:- Improvement after scar revision.

\begin{tabular}{|c|c|c|c|}
\hline S.no. & Results & Number & Percentage \\
\hline 1 & Excellent & 57 & $60 \%$ \\
\hline 2 & Moderate & 29 & $30 \%$ \\
\hline 3 & Minimal & 10 & $10 \%$ \\
\hline
\end{tabular}

Complications seen in our study was minimal, including haematoma formation, secondary infection and delayed healing seen in $5 \%$ patients each. (Table 4 ) 
Table 4:- Complications of scar revision.

\begin{tabular}{|c|c|c|c|}
\hline S.no. & Complications & Number & Percentage \\
\hline 1 & Haematoma formation & 5 & $5 \%$ \\
\hline 2 & Secondary infection & 5 & $5 \%$ \\
\hline 3 & Delayed healing & 5 & $5 \%$ \\
\hline
\end{tabular}

\section{Discussion:-}

Scar revision is unique in the spectrum of facial plastic and reconstructive surgery. Patients who are candidates for scar revision procedures often present after significant loss of regional tissue or due to wound closure done by less experienced surgeon's and poor post injury wound management. There are various techniques of scar revision including Z plasty, VY plasty, Wplasty and geometric broken line closure. An overview on these techniques are discussed as follows

\section{Z plasty:-}

It is a double transposition flap where the scar to be excised lies along the central limb of the $\mathrm{Z}$ with two peripheral limbs parallel to each other ${ }^{11}$. After transposition, the centre Z-plasty is one of the most versatile scar revision techniques available. As a transposition flap, Z-plasty allows for 2 adjacent undermined triangular flaps, constructed from the same central axis, to transpose over each other and to lie in the other's originating bed (Figure 1). In essence, these 2 triangular flaps are transposed from areas of relative excess into areas of relative deficiency and eventually lie at near right angles to the original central axis. The usefulness of Z-plasty in scar revision rests in its ability to reorient a scar to lie more favorably in the direction of RSTLs; reorient the scar or anatomic landmark into a more favorable location or position; break up the length of the scar, thereby rendering it less visible; increase the scar length (ie, lengthen a contracted scar), thereby decreasing the prevailing scar contractile force and permitting better conformation to contoured surfaces and allow the surface-revised scar to run in a different angle to the deeper, more established scar, thus decreasing the tendency of the final scar to become depressed ${ }^{12}$.
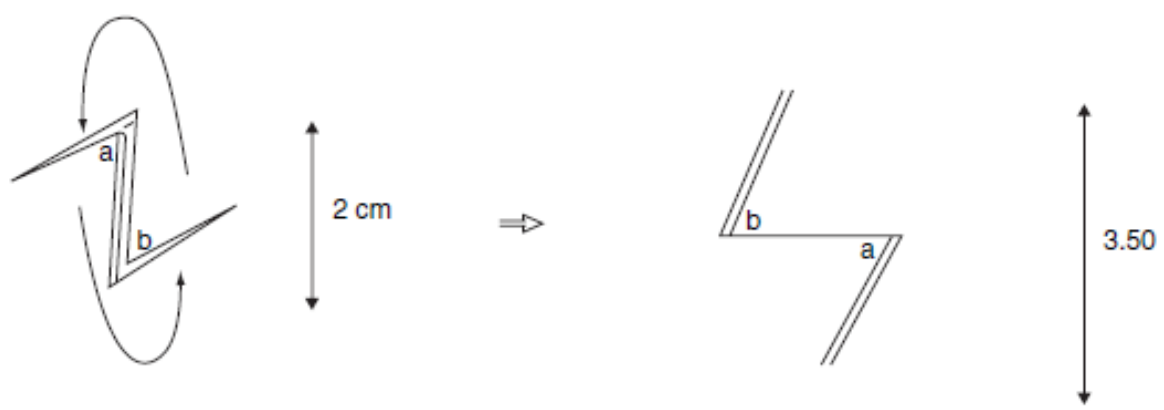

Figure 1:- Z-plasty rearrangement designed on $60^{\circ}$ flap angle to produce $75 \%$ gain in length along common axis.

\section{W Plasty:-}

It is designed to make a linear scar irregular, such that majority of the limbs lie along RSTL. While performing the W plasty, some amount of normal tissue is excised along with the scar such that the final scar is irregular, in the shape of multiple W's lined side-by-side ${ }^{13}$. The $\mathrm{W}$ plasty consists of multiple small triangular advancement flaps on either sides of the scar such that the closure occurs in an interdigitating fashion (Figure 2). The advantages of $\mathrm{W}$ plasty are that it is easy to plan and execute and It breaks a straight scar into multiple small segments many of whom lie along the RSTL ${ }^{1}$. There are various disadvantages of W plasty- it may lead to a longer scar, it needs adjacent tissue laxity and sometimes regular repetitive pattern makes the scar noticeable $\mathrm{W}$-plasty. The primary utility of the

W-plasty (also termed the running W-plasty or zig-zag plasty) is in rendering a lengthy linear scar irregular. In addition to linear scar revision, the W-plasty is useful in the closure of semicircular incisions in which the sweeping unbroken curvilinear scar is more noticeable and under greater tension and, thus, over time more likely to become depressed or pincushioned. Note that while the W-plasty makes irregular a linear scar and spares unwanted lengthening that may arise fromusing small multiple Z-plasties, the final result is often readily visible because the eye easily can follow the predictable zig-zag configuration ${ }^{14}$. Finally, in its 
basic execution, this technique incorporates neither transposition nor rotation of adjacent flaps; therefore, the final scar is not elongated but only increased in the final total length.

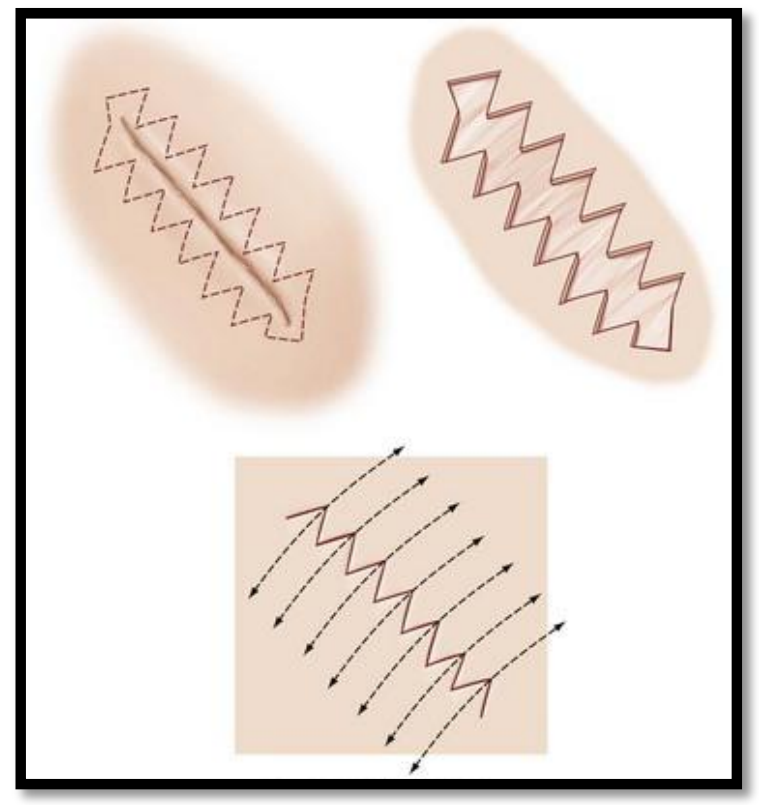

Figure 2:- W Platy technique.

\section{V-Y Plasty:-}

The V-Y plasty is a popular technique for skin lengthening. Its most desirable feature is that it allows some variability in the amount of length achieved. It is most appropriate in situations where previous scar contracture is not a factor. The procedure includes a "V" shaped incision (Figure 3). The wider the angle of the "V", the better blood supply there is to the flat tip. In the foot, the apex of the" $\mathrm{V}$ " should be distal in order to ensure an adequate blood supply to the flat tip. Distal skin is then advanced to the desired position, creating a " $\mathrm{Y}$ " incision. The entire "Y" flap may be undermined beneath the superficial fascia for exposure purposes.

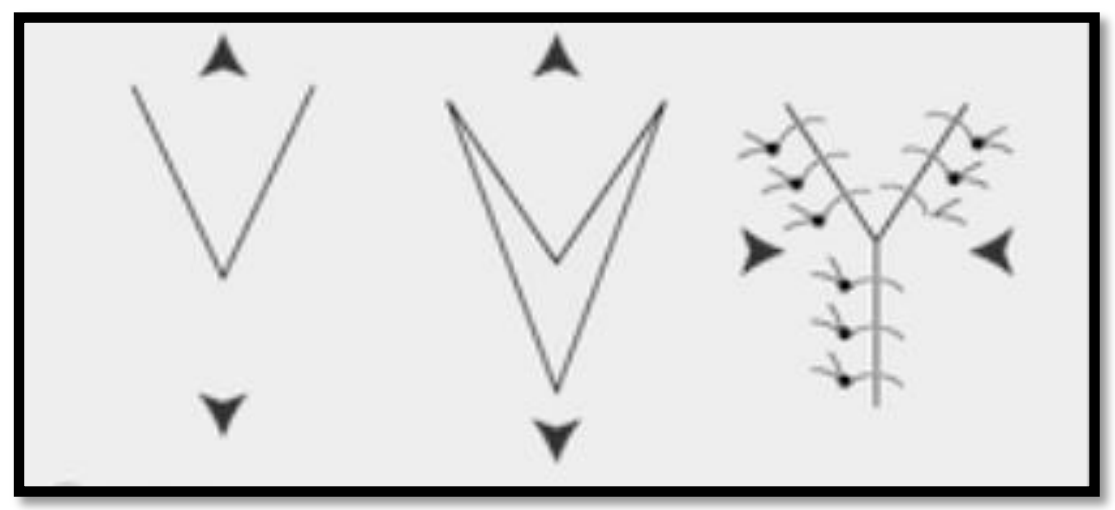

Figure 3:- V-Y plasty technique.

\section{Conclusion:-}

Scarring is an inevitable and necessary aspect of healing. There are many techniques that can be utilized for scar revision and prevention. An appropriate knowledge of skin physiology and biomechanics, facial aesthetic principles, and the surgical geometry of soft-tissue surgery can help minimize the scarring that may occur with patients or help revise the scarring that they endure from other causes. 


\section{References:-}

1. Shockley WW. Scar revision techniques. Oper Tech Otolaryngol Head Neck Surg. 2011;22:84-93.

2. Cupp CL, Johnson MB, Larrabee WF. Scar revision. Facial Plast Surg Clin North Am. 1998;6:195-201.

3. Davidson TM. Lacerations and Scar Revision. In: Cummings, ed., Otolaryngology: Head and Neck Surgery. 3rd ed. Mosby-Year Book, 1998.

4. Clark RA. Basics of cutaneous wound repair. J Dermatol Surg Oncol 1993; 19(8):693-706.

5. Moran ML. Scar revision. Otolaryngol Clin North Am 2001; 34(4):767-780.

6. Niessen FB, Spauwen PH, Schalkwijk J, Kon M. On the nature of hypertrophic scars and keloids: a review. Plast Reconstr Surg 1999; 104(5):1435-1458.

7. Sherris DA, Larrabee WF Jr, Murakami CS. Management of scar contractures, hypertrophic scars, and keloids. Otolaryngol Clin North Am 1995; 28(5):1057-1068.

8. Inalsingh CH. An experience in treating five hundred and one patients with keloids. Johns Hopkins Med J 1974; 134(5):284-290.

9. Lindsey WH, Davis PT. Facial keloids. A 15-year experience. Arch Otolaryngol Head Neck Surg 1997; 123(4):397-400.

10. Blackburn WR, Cosman B. Histologic basis of keloid and hypertrophic scar differentiation. Clinicopat hologic correlation. Arch Pathol 1966; 82(1):65-71.

11. Rohrich RJ, Zbar RI. A simplifi ed algorithm for the use of Z-plasty. Plast Reconstr Surg. 1999;103:1513-7.

12. Rodgers BJ, Williams EF, Hove CR. W-Plasty and geometric broken line closure. Facial Plast Surg. 2001;17:239-44.

13. Borges AF. W-plasty. Ann Plast Surg. 1979;3:153-9.

14. Park SS. Scar revision through W-plasty. Facial Plast Surg Clin North Am. 1998;6:157-61. 